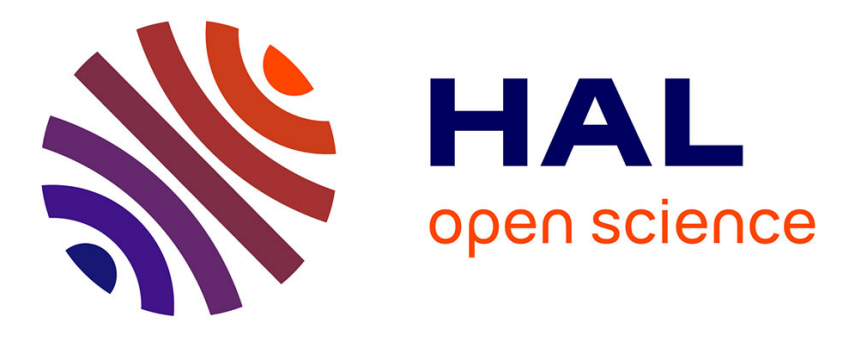

\title{
Chromogranins as molecular coordinators at the crossroads between hormone aggregation and secretory granule biogenesis
}

Ophélie Carmon, Fanny Laguerre, Lydie Jeandel, Youssef Anouar, Maite Montero-Hadjadje

\section{To cite this version:}

Ophélie Carmon, Fanny Laguerre, Lydie Jeandel, Youssef Anouar, Maite Montero-Hadjadje. Chromogranins as molecular coordinators at the crossroads between hormone aggregation and secretory granule biogenesis. Chromogranins: from cell biology to physiology, Springer, pp.39-48, 2017, 978-3319-58338-9. hal-02336001

HAL Id: hal-02336001

https://hal-normandie-univ.archives-ouvertes.fr/hal-02336001

Submitted on 28 Oct 2019

HAL is a multi-disciplinary open access archive for the deposit and dissemination of scientific research documents, whether they are published or not. The documents may come from teaching and research institutions in France or abroad, or from public or private research centers.
L'archive ouverte pluridisciplinaire HAL, est destinée au dépôt et à la diffusion de documents scientifiques de niveau recherche, publiés ou non, émanant des établissements d'enseignement et de recherche français ou étrangers, des laboratoires publics ou privés. 


\title{
Chromogranins as Molecular Coordinators at the Crossroads between Hormone Aggregation and Secretory Granule Biogenesis
}

\author{
O. Carmon, F. Laguerre, L. Jeandel, Y. Anouar, and M. Montero-Hadjadje
}

\begin{abstract}
Chromogranins are members of a family of soluble glycoproteins sharing common structural features and properties, known to be inducers of prohormone aggregation and sorting into secretory granules. There is now increasing evidence for a key role of chromogranins in hormone sorting to the regulated secretory pathway, resulting from the interaction of chromogranin-induced aggregates with the TGN membrane through either sorting receptors such as carboxypeptidase E, or lipids such as cholesterol. These molecular interactions would contribute to the TGN membrane remodeling, a prerequisite to the recruitment of cytosolic proteins inducing membrane curvature and consecutive secretory granule budding. The identification of the molecular cues involved in the biogenesis of secretory granules is currently under intense investigation. The diversity of chromogranins sharing common structural features but with possible non-redundant functions implies a variety of secretory granule populations whose existence and function remain to be established in a given neuroendocrine cell type.

The present chapter deals with the role of the different members of the chromogranin family in the processes of hormone aggregation, secretory granule biogenesis, and hormone sorting through their interaction with the TGN membrane. Finally, the alteration of chromogranin secretion is described in pathophysiological conditions linked to dysregulated hormone secretion.
\end{abstract}

\section{Introduction}

The production and release of neurohormones by neuroendocrine cells are crucial for the coordination of the physiological functions governing organisms. Neurohormones are molecular mediators that are stored in vesicular organelles, called secretory granules, generated by budding of the trans-Golgi network (TGN)

O. Carmon $\bullet$ F. Laguerre $\bullet$ L. Jeandel $\bullet$ Y. Anouar $(\bowtie) \bullet$ M. Montero-Hadjadje Inserm U1239, University of Rouen-Normandy, UNIROUEN, Institute for Research and Innovation in Biomedicine, Mont-Saint-Aignan, France

e-mail: youssef.anouar@univ-rouen.fr 
membrane. The predominant components found in secretory granules are chromogranins including chromogranin A $(\mathrm{CgA})$, chromogranin B $(\mathrm{CgB})$ also named secretogranin I (SgI), secretogranin II (SgII), SgIII, 7B2 (SgV), NESP55 (SgVI), VGF (SgVII), and proSAAS (SgVIII), which constitute a family of soluble phospho-glycoproteins with similar structural features that confer to these proteins common functional attributes in the biogenesis of secretory granules and the sorting of prohormones. Indeed, chromogranins exhibit a high proportion of acidic amino acids and a high capacity to bind calcium, which support their ability to aggregate with each other and with neuropeptides in the low $\mathrm{pH}$ and high calcium conditions found in the TGN (Elias et al. 2010). Chromogranins also exhibit several dibasic sites which are the targets of processing enzymes, leading to the formation of biologically active peptides (Metz-Boutigue et al. 1993; MonteroHadjadje et al. 2008) but also acting as sorting receptors for chromogranininduced aggregates in order to direct them to secretory granules (Elias et al. 2010). These proteins are also able to concentrate catecholamines inside the secretory granules to control their release during the exocytotic process (Machado et al. 2010). In this chapter, we will provide a brief update on the central role of chromogranins in the concomitant molecular phenomena involved in the formation of secretory granules (molecular aggregation, sorting of hormone aggregates and budding of the TGN membrane) and leading to the establishment of the regulated secretory pathway in neuroendocrine cells.

\section{I/ The Twenty-First Century, the Advent of Chromogranins as Critical Regulators of Secretory Granule Biogenesis}

To date, several members of the chromogranin family are known to play an active role in the formation of secretory granules. The pioneer study was performed using an antisens RNA strategy to knockdown CgA expression in neuroendocrine PC12 cells, which showed a drastic reduction of secretory granule number (Kim et al. 2001). Following this initial observation, two strains of $\mathrm{CgA}$ knockout mice were generated which diverged for the outcome of secretory granules but which both exhibited hypertension due to an increase in circulating catecholamine levels (Mahapatra et al. 2005, Hendy et al. 2006). These data suggested therefore the existence of a link between $\mathrm{CgA}$ expression and the biogenesis of functional secretory granules. Interestingly, disruption of the $\mathrm{CgB}$ gene in mice revealed a similar phenotype in pancreatic and chromaffin cells regarding the secretory granule number, with a defective secretion of islet hormones and catecholamines (Obermüller et al. 2010, Díaz-Vera et al. 2010). Similarly, knockdown of SgII expression leads to a decrease in the number of secretory granules in PC12 cells (Courel et al. 2010). 
Genetic ablation of SgIII in mice caused no apparent defects despite the ubiquitous expression of SgIII in neuroendocrine cells and tissues (Kingsley et al. 1990). In SgIII-deficient AtT20 cells, the intracellular retention of $\mathrm{CgA}$ and proopiomelanocortin (POMC) were impaired, but residual adrenocorticotropic hormone (ACTH)/ POMC together with SgII were still localized to the remaining secretory granules, and were secreted in a regulated manner (Sun et al. 2013). The role of a less known member of the chromogranin family, VGF, in secretory granule biogenesis has been investigated more recently (Fargali et al. 2014). In this study, VGF-knockout mice exhibited decreased secretory granule size in noradrenergic chromaffin cells, decreased adrenal $\mathrm{CgB}$ and increased plasma epinephrine leading to hypertension, while knock-in of human VGF1-615 rescued the hypertensive knockout phenotype. Interestingly, knock-in of human VGF1-524, that lacks C-terminal peptide TLQP-21, resulted in a significant increase in blood pressure and infusion of TLQP-21 normalized hypertension. Together, these studies indicate that chromogranins and chromogranin-derived peptides may have redundant and non-redundant roles in the regulated secretory pathway, and in the regulation of catecholamine levels and blood pressure.

\section{II/ Hormone Aggregation as the First Function Assigned to Chromogranins}

After their biosynthesis in the rough endoplasmic reticulum, chromogranins are transported and stored as soluble glycoproteins in the TGN lumen which exhibits high calcium concentration (10-15 mM) and low $\mathrm{pH}$ (6-6.5) (Kim et al. 2006). Chromogranins share several structural properties that are conserved during evolution, such as global acidity that enables them to bind calcium with low affinity and high capacity (Taupenot et al. 2003). A structural analysis of $\mathrm{CgA}$ revealed that in the conditions of the TGN lumen, $\mathrm{CgA}$ can adopt a coiledcoil structure which promotes the initiation of a core for aggregate nucleation (Mosley et al. 2007). Besides, $\mathrm{CgA}$ and $\mathrm{CgB}$ exhibit a N-terminal disulfidebonded loop which has been shown to contribute to the aggregation with prohormones at low pH (Chanat and Huttner 1991, Thiele and Huttner 1998). On the other hand, the C-terminal domain of $\mathrm{CgA}$ is involved in calcium/pH-dependent homodimerization/homotetramerization (Yoo and Lewis 1993), allowing the aggregation-mediated sorting of $\mathrm{CgA}$ to secretory granules (Cowley et al. 2000). These aggregates of high molecular weight sort away prohormones from constitutively secreted proteins (Dannies 2001). Homophilic or heterophilic aggregation is related to the tertiary conformation of the prohormones which direct specific interactions to give rise to various secretory granule populations in a same cell type (Kim et al. 2006). 


\section{III/ Hormone Sorting through Interaction of Chromogranins with the TGN Membrane}

Concomitant to the process of hormone aggregation, chromogranin-induced aggregates interact with the TGN membrane through either sorting receptors or lipids (Fig. 1a). Indeed, secretogranin III (SgIII) interacts with cholesterol in lipid rafts (Hosaka et al. 2004) and with the modifying enzyme and membrane-associated carboxypeptidase E (CPE) (Hosaka et al. 2005). Since CgA has been shown to bind to SgIII (Hosaka et al. 2002), SgIII-cholesterol interaction results in the sorting of CgAinduced aggregates to the granules of the regulated secretory pathway. A recent work by Sun et al. (2013) has suggested a role for SgII as a protein with potential for sorting POMC, suggesting that endocrine cells may have developed a system of redundancy with multiple sorting systems that can partially or completely compensate for each other with the ultimate capacity of ensuring hormone delivery, as also proposed for CPE and SgIII in CgA and POMC sorting (Cawley et al. 2016).

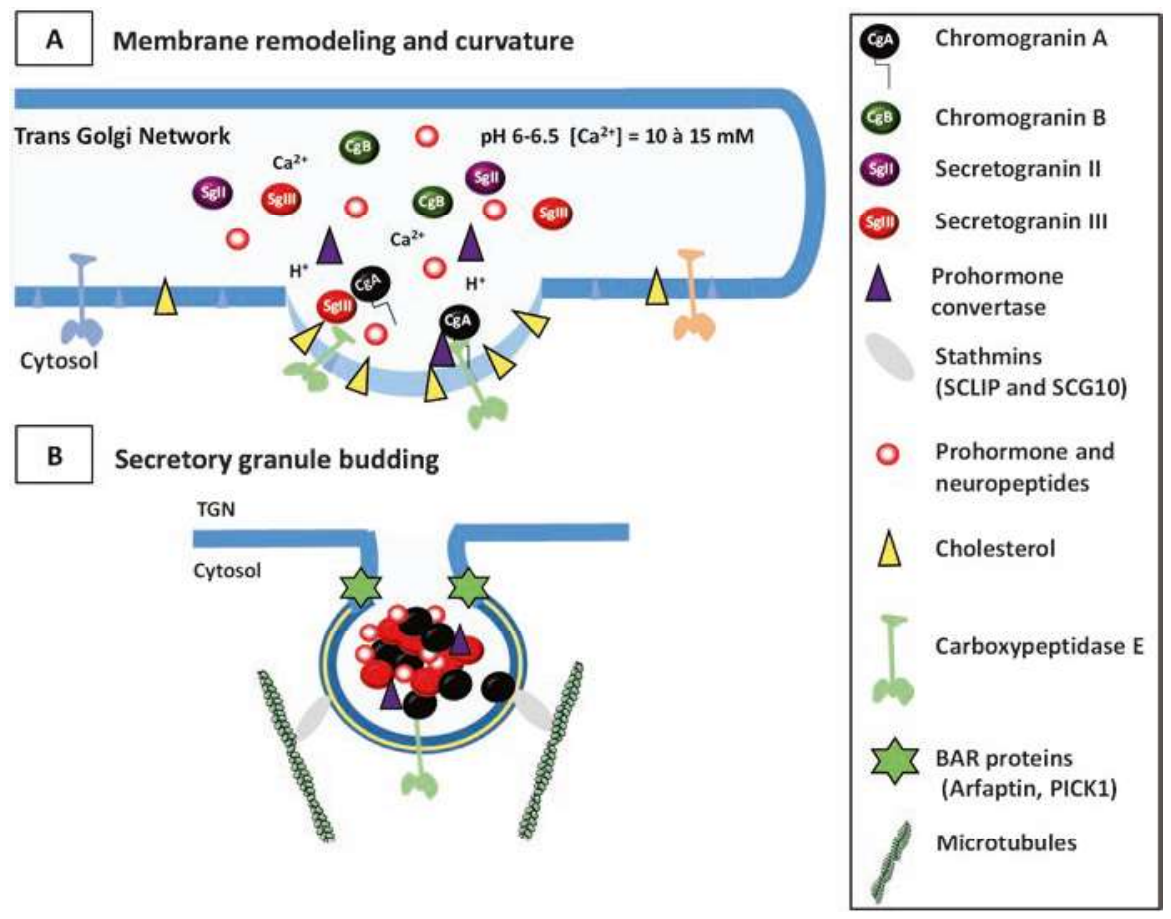

Fig. 1 Proposed model of chromogranin involvement in secretory granule biogenesis from TGN compartment. (a) Chromogranins induce the remodeling of the TGN membrane by interacting with distinct components: $\mathrm{SgIII}$ interacts with $\mathrm{CgA}$, cholesterol and carboxypeptidase E. CgA also interacts with CPE. (b) At the cytosolic side of the TGN membrane, BAR proteins and stathmins are recruited to facilitate respectively the fission and the transfer to microtubules of nascent $\mathrm{CgA}$ containing secretory granules for their transport towards the cell periphery 
Their primary sequence exhibiting several dibasic sites, chromogranins are the substrates for intragranular prohormone-converting enzymes. Prohormone convertases are associated with cholesterol-rich lipid microdomains through $\alpha$ helices-rich hydrophobic domain(s) identified in their C-terminal part, thus acting as receptors that carry chromogranin-induced hormone aggregates to secretory granules (Dikeakos and Reudelhuber 2007).

Surprisingly, using a transcriptome/proteome-wide approach and coimmunoprecipitation experiments, SCLIP and SCG10 stathmins, cytosolic proteins known as regulators of microtubule polymerization, were identified as partners of CgA (Mahapatra et al. 2008). In this study, SCLIP and SCG10 were colocalized to the Golgi apparatus of chromaffin cells and their down-regulation altered chromaffin cell granules and abolished the level of secretion of endogenous $\mathrm{CgA}, \mathrm{SgII}$ and $\mathrm{CgB}$. Other cytosolic proteins are capable of sensing, inducing, and/or stabilizing membrane curvature through Bin/Amphiphysin/Rvs (BAR) domains which are crescent-shaped, dimeric $\alpha$-helical modules and could thus participate to secretory granule formation (Frost et al. 2009, Rao and Haucke 2011). Recently, two members of this family, arfaptin 1 and PICK1, were related to the biogenesis of CgAcontaining secretory granules through their binding to TGN membrane lipids (Fig. 1b) (Gehart et al. 2012, Cruz-Garcia et al. 2013, Holst et al. 2013, Pinheiro et al. 2014). Altogether, these data suggest that chromogranins influence the molecular organization of the TGN membrane to induce the recruitment of membrane and cytosolic proteins necessary for the budding of functional secretory granules, but the mechanism of action and the chronology of induced molecular events remain to be elucidated.

\section{IV/ Are Chromogranins Linked to Hypersecretory Endocrine Pathologies?}

Ubiquitous distribution of chromogranins in endocrine and neuroendocrine tissue from which they are secreted into the bloodstream, makes chromogranins useful markers of normal and tumoral neuroendocrine cells. In fact, multiple studies have documented the clinical value of detecting chromogranins and their derived peptides in tissues and measuring their circulating levels (Taupenot et al. 2003, Bartolomucci et al. 2011). Measurement of plasma chromogranins and derived peptide levels can be used to diagnose or monitor the progression of neuroendocrine tumors, the highest accuracy being observed in tumors characterized by an intense secretory activity (Guérin et al. 2010, Guillemot et al. 2006, 2014). This is the case of pheochromocytomas which are catecholamine-producing neoplasms arising from chromaffin cells of the adrenal medulla, leading to several clinical manifestations due to the actions of excess catecholamines, such as essential hypertension. Interestingly, the SgII-derived peptide EM66 has been established as a valuable 
marker to distinguish benign and malignant pheochromocytomas (Yon et al. 2003, Guillemot et al. 2006). Serum CgA has been also well documented as a marker for sympathoadrenal activity underlying cardiovascular regulation and essential hypertension (O'Connor and Bernstein 1984; Takiyyuddin et al. 1994) along with catecholamines, as well as severe inflammatory diseases such as sepsis and systemic inflammatory response syndrome (Zhang et al. 2008). Moreover, it has been shown that $\mathrm{CgA}$ genetic variants may cause profound changes in human autonomic activity, and may associate with the risk of developing hypertension (Rao et al. 2007, Chen et al. 2008), suggesting a link between CgA expression, catecholamine secretion and blood pressure regulation.

Furthermore, Colombo et al. (2002) have shown that CgA expression in neoplastic cells affects tumor growth and morphogenesis in mouse models, suggesting that abnormal secretion of $\mathrm{CgA}$ by neuroendocrine neoplastic cells could affect tumorigenic processes. A very interesting study based on the comparison of normotensive and hypertensive patients with pheochromocytoma revealed lower urinary catecholamines and a global decreased chromaffin gene expression, including SgII, in tumors from normotensive patients (Haissaguerre et al. 2013). In line with a potential link between SgII, hormone secretion and tumorigenesis, we have recently demonstrated that SgII is expressed in prostate cancer, that its increased levels correlate with high grade tumors and that its expression triggers a neuroendocrine differentiation of prostatic tumor cells as revealed by the appearance of secretory granules and a secretory activity. Because neuroendocrine differentiation is associated with a poor prognosis, these data suggest that SgII-induced secretion may play a pivotal role in prostate cancer progression (Courel et al. 2014).

Chromogranins seem to be also implicated in the alteration of hormone secretion observed in the context of metabolic disorders. Indeed, $\mathrm{CgA}$ knockout mice display increased adiposity and high levels of circulating leptin and catecholamines. As in diet-induced obese mice, desensitization of leptin receptors caused by hyperleptinemia is believed to contribute to the obese phenotype of these $\mathrm{KO}$ mice (Bandyopadhyay et al. 2012). In small bowel Crohn's disease, glucagon-like peptide 1 and CgA-immunopositive cells were significantly increased with appreciable mRNA increases for $\mathrm{CgA}$, glucagon-like peptide 1 and Neurogenin 3 , an enteroendocrine transcription factor, indicating an enhanced enteroendocrine cell activity (Moran et al. 2012). In accordance, modifications of $\mathrm{CgA}$-immunoreactive cell density were also observed in the small intestine epithelium of patients with irritable bowel syndrome (IBS) after receiving dietary guidance, which may reflect a change in the densities of the small intestinal enteroendocrine cells, suggesting the contribution of their secretory activity to the improvement in the IBS symptoms (Mazzawi and El-Salhy 2016). Furthermore, the knockout of the $\mathrm{CgB}$ gene in mice provoked a reduction in stimulated secretion of insulin, glucagon and somatostatin in pancreatic islets, and consequently $\mathrm{CgB}-\mathrm{KO}$ animals display some hallmarks of human type-2 diabetes (Obermüller et al. 2010). 


\section{Concluding Remarks}

While aggregation ability of chromogranins allows the segregation of secretory granule cargo proteins, the anchor of the chromogranin-bound cargo proteins to the TGN membrane as the secretory granule forms or matures seems to result from a less universal mechanism. The study of chromogranin-expressing cells, which possess multiple types of secretory granules and thus the ability to selectively secrete different cocktails of biologically active components (Dannies 2001), may be informative on the variety of existing chromogranin-mediated sorting mechanisms. The identification of the membrane patches into the TGN recognized by the protein cargo, and the understanding of their interactions with cytosolic proteins would help to describe the transport, docking at the membrane, and exocytosis of secretory granules. What is already known is that chromogranins and their conserved domains are not only important for promoting the biogenesis of secretory granules, but also for the targeting and release of hormones through the regulated secretory pathway (Gondré-Lewis et al. 2012). These findings raise the interesting possibility that chromogranins could be relevant factors in the formation of secretory granules, probably by promoting the interactions between the secretory granule membrane and cytosolic proteins. Because several studies performed on neuroendocrine cells have provided clues regarding the redundant and non-redundant roles of chromogranins and chromogranin-derived peptides in the regulated secretory pathway, non-endocrine cell models or endocrine cell models devoid of a regulated secretory pathway expressing chromogranins could constitute useful and appropriate tools to further characterize the molecular mechanisms by which each chromogranin contributes to or establishes a regulated secretory pathway. The increasing evidence showing that chromogranins are crucial actors impacted in many diseases related to endocrine disruption indicates that chromogranins should be considered more than disease markers and warrants further studies to unravel their molecular mechanism of action and thereby to identify novel therapeutical strategies for the treatment of various pathologies including neuroendocrine tumors, essential hypertension and/or metabolic disorders which are increasingly affecting the populations.

\section{References}

Bandyopadhyay GK, Vu CU, Gentile S, Lee H, Biswas N, Chi N-W, O'Connor DT, Mahata SK (2012) Catestatin (chromogranin A(352-372)) and novel effects on mobilization of fat from adipose tissue through regulation of adrenergic and leptin signaling. J Biol Chem 287:23141-23151

Bartolomucci A, Possenti R, Mahata SK, Fischer-Colbrie R, Loh YP, Salton SRJ (2011) The extended granin family: structure, function, and biomedical implications. Endocr Rev $32: 755-797$ 
Cawley NX, Rathod T, Young S, Lou H, Birch N, Loh YP (2016) Carboxypeptidase E and secretogranin III coordinately facilitate efficient sorting of proopiomelanocortin to the regulated secretory pathway in AtT20 cells. Mol Endocrinol 30:37-47

Chanat E, Huttner WB (1991) Milieu-induced, selective aggregation of regulated secretory proteins in the trans-Golgi network. J Cell Biol 115:1505-1519

Chen Y, Rao F, Rodriguez-Flores JL et al (2008) Naturally occurring human genetic variation in the $3^{\prime}$-untranslated region of the secretory protein chromogranin $\mathrm{A}$ is associated with autonomic blood pressure regulation and hypertension in a sex-dependent fashion. J Am Coll Cardiol 52:1468-1481

Colombo B, Curnis F, Foglieni C, Monno A, Arrigoni G, Corti A (2002) Chromogranin A expression in neoplastic cells affects tumor growth and morphogenesis in mouse models. Cancer Res 62:941-946

Courel M, Soler-Jover A, Rodriguez-Flores JL, Mahata SK, Elias S, Montero-Hadjadje M, Anouar Y, Giuly RJ, O'Connor DT, Taupenot L (2010) Pro-hormone secretogranin II regulates dense core secretory granule biogenesis in catecholaminergic cells. J Biol Chem 285:10030-10043

Courel M, El Yamani F-Z, Alexandre D et al (2014) Secretogranin II is overexpressed in advanced prostate cancer and promotes the neuroendocrine differentiation of prostate cancer cells. Eur J Cancer 50:3039-3049

Cowley DJ, Moore YR, Darling DS, Joyce PB, Gorr SU (2000) N- and C-terminal domains direct cell type-specific sorting of chromogranin A to secretory granules. J Biol Chem 275:7743-7748

Cruz-Garcia D, Ortega-Bellido M, Scarpa M, Villeneuve J, Jovic M, Porzner M, Balla T, Seufferlein T, Malhotra V (2013) Recruitment of arfaptins to the trans-Golgi network by PI(4)P and their involvement in cargo export. EMBO J 32:1717-1729

Dannies PS (2001) Concentrating hormones into secretory granules: layers of control. Mol Cell Endocrinol 177:87-93

Díaz-Vera J, Morales YG, Hernández-Fernaud JR, Camacho M, Montesinos MS, Calegari F, Huttner WB, Borges R, Machado JD (2010) Chromogranin B gene ablation reduces the catecholamine cargo and decelerates exocytosis in chromaffin secretory vesicles. J Neurosci 30:950-957

Dikeakos JD, Reudelhuber TL (2007) Sending proteins to dense core secretory granules: still a lot to sort out: Figure 1. J Cell Biol 177(2):191-196

Elias S, Delestre C, Ory S, Marais S, Courel M, Vazquez-Martinez R, Bernard S, Coquet L, Malagon MM, Driouich A, Chan P, Gasman S, Anouar Y, Montero-Hadjadje M (2012) Chromogranin A Induces the Biogenesis of Granules with Calcium- and Actin-Dependent Dynamics and Exocytosis in Constitutively Secreting Cells. Endocrinol 153(9):4444-4456

Fargali S, Garcia AL, Sadahiro M et al (2014) The granin VGF promotes genesis of secretory vesicles, and regulates circulating catecholamine levels and blood pressure. FASEB J 28:2120-2133

Frost A, Unger VM, De Camilli P (2009) The BAR domain superfamily: membrane-molding macromolecules. Cell 137:191-196

Gehart H, Goginashvili A, Beck R, Morvan J, Erbs E, Formentini I, De Matteis MA, Schwab Y, Wieland FT, Ricci R (2012) The BAR domain protein Arfaptin-1 controls secretory granule biogenesis at the trans-Golgi network. Dev Cell 23:756-768

Gondré-Lewis MC, Park JJ, Loh YP (2012) Cellular mechanisms for the biogenesis and transport of synaptic and dense-core vesicles. Int Rev Cell Mol Biol 299:27-115

Guérin M, Guillemot J, Thouënnon E et al (2010) Granins and their derived peptides in normal and tumoral chromaffin tissue: implications for the diagnosis and prognosis of pheochromocytoma. Regul Pept 165:21-29

Guillemot J, Anouar Y, Montero-Hadjadje M et al (2006) Circulating EM66 is a highly sensitive marker for the diagnosis and follow-up of pheochromocytoma. Int J Cancer 118:2003-2012

Guillemot J, Guérin M, Thouënnon E, Montéro-Hadjadje M, Leprince J, Lefebvre H, Klein M, Muresan M, Anouar Y, Yon L (2014) Characterization and plasma measurement of the WE-14 peptide in patients with pheochromocytoma. PLoS One 9:e88698

Haissaguerre M, Courel M, Caron P et al (2013) Normotensive incidentally discovered pheochromocytomas display specific biochemical, cellular, and molecular characteristics. J Clin Endocrinol Metab 98:4346-4354 
Hendy GN, Li T, Girard M, Feldstein RC, Mulay S, Desjardins R, Day R, Karaplis AC, Tremblay ML, Canaff L (2006) Targeted ablation of the chromogranin a (Chga) gene: normal neuroendocrine dense-core secretory granules and increased expression of other granins. Mol Endocrinol 20:1935-1947

Holst B, Madsen KL, Jansen AM et al (2013) PICK1 deficiency impairs secretory vesicle biogenesis and leads to growth retardation and decreased glucose tolerance. PLoS Biol 11:e1001542

Hosaka M, Watanabe T, Sakai Y, Uchiyama Y, Takeuchi T (2002) Identification of a chromogranin A domain that mediates binding to secretogranin III and targeting to secretory granules in pituitary cells and pancreatic beta-cells. Mol Biol Cell 13:3388-3399

Hosaka M, Suda M, Sakai Y, Izumi T, Watanabe T, Takeuchi T (2004) Secretogranin III binds to cholesterol in the secretory granule membrane as an adapter for chromogranin A. J Biol Chem 279:3627-3634

Hosaka M, Watanabe T, Sakai Y, Kato T, Takeuchi T (2005) Interaction between secretogranin III and carboxypeptidase E facilitates prohormone sorting within secretory granules. J Cell Sci 118:4785-4795

Kim T, Tao-Cheng JH, Eiden LE, Loh YP (2001) Chromogranin A, an "on/off” switch controlling dense-core secretory granule biogenesis. Cell 106:499-509

Kim T, Gondré-Lewis MC, Arnaoutova I, Loh YP (2006) Dense-core secretory granule biogenesis. Physiology (Bethesda) 21:124-133

Kingsley DM, Rinchik EM, Russell LB, Ottiger HP, Sutcliffe JG, Copeland NG, Jenkins NA (1990) Genetic ablation of a mouse gene expressed specifically in brain. EMBO J 9:395-399

Machado JD, Díaz-Vera J, Domínguez N, Alvarez CM, Pardo MR, Borges R (2010) Chromogranins $\mathrm{A}$ and $\mathrm{B}$ as regulators of vesicle cargo and exocytosis. Cell Mol Neurobiol 30:1181-1187

Mahapatra NR, O'Connor DT, Vaingankar SM et al (2005) Hypertension from targeted ablation of chromogranin A can be rescued by the human ortholog. J Clin Invest 115:1942-1952

Mahapatra NR, Taupenot L, Courel M, Mahata SK, O’Connor DT (2008) The trans-Golgi proteins SCLIP and SCG10 interact with chromogranin A to regulate neuroendocrine secretion. Biochemistry 47:7167-7178

Mazzawi T, El-Salhy M (2016) Changes in small intestinal chromogranin A-immunoreactive cell densities in patients with irritable bowel syndrome after receiving dietary guidance. Int $\mathrm{J}$ Mol Med 37:1247-1253

Metz-Boutigue MH, Garcia-Sablone P, Hogue-Angeletti R, Aunis D (1993) Intracellular and extracellular processing of chromogranin A. Determination of cleavage sites. Eur J Biochem 217:247-257

Montero-Hadjadje M, Vaingankar S, Elias S, Tostivint H, Mahata SK, Anouar Y (2008) Chromogranins $\mathrm{A}$ and $\mathrm{B}$ and secretogranin II: evolutionary and functional aspects. Acta Physiol (Oxf) 192:309-324

Moran GW, Pennock J, McLaughlin JT (2012) Enteroendocrine cells in terminal ileal Crohn's disease. J Crohns Colitis 6:871-880

Mosley CA, Taupenot L, Biswas N et al (2007) Biogenesis of the secretory granule: chromogranin A coiled-coil structure results in unusual physical properties and suggests a mechanism for granule core condensation. Biochemistry 46:10999-11012

O'Connor DT, Bernstein KN (1984) Radioimmunoassay of chromogranin A in plasma as a measure of exocytotic sympathoadrenal activity in normal subjects and patients with pheochromocytoma. N Engl J Med 311:764-770

Obermüller S, Calegari F, King A et al (2010) Defective secretion of islet hormones in chromogranin-B deficient mice. PLoS One 5:e8936

Pinheiro PS, Jansen AM, de Wit H, Tawfik B, Madsen KL, Verhage M, Gether U, Sørensen JB (2014) The BAR domain protein PICK1 controls vesicle number and size in adrenal chromaffin cells. J Neurosci 34:10688-10700

Rao Y, Haucke V (2011) Membrane shaping by the Bin/amphiphysin/Rvs (BAR) domain protein superfamily. Cell Mol Life Sci 68:3983-3993

Rao F, Wen G, Gayen JR et al (2007) Catecholamine release-inhibitory peptide catestatin (chromogranin A(352-372)): naturally occurring amino acid variant Gly364Ser causes profound changes in human autonomic activity and alters risk for hypertension. Circulation 115:2271-2281 
Sun M, Watanabe T, Bochimoto H, Sakai Y, Torii S, Takeuchi T, Hosaka M (2013) Multiple sorting systems for secretory granules ensure the regulated secretion of peptide hormones. Traffic 14:205-218

Takiyyuddin MA, Brown MR, Dinh TQ, Cervenka JH, Braun SD, Parmer RJ, Kennedy B, O'Connor DT (1994) Sympatho-adrenal secretion in humans: factors governing catecholamine and storage vesicle peptide co-release. J Auton Pharmacol 14:187-200

Taupenot L, Harper KL, O'Connor DT (2003) The chromogranin-secretogranin family. N Engl J Med 348:1134-1149

Thiele C, Huttner WB (1998) The disulfide-bonded loop of chromogranins, which is essential for sorting to secretory granules, mediates homodimerization. J Biol Chem 273:1223-1231

Yon L, Guillemot J, Montero-Hadjadje M, Grumolato L, Leprince J, Lefebvre H, Contesse V, Plouin P-F, Vaudry H, Anouar Y (2003) Identification of the secretogranin II-derived peptide EM66 in pheochromocytomas as a potential marker for discriminating benign versus malignant tumors. J Clin Endocrinol Metab 88:2579-2585

Yoo SH, Lewis MS (1993) Dimerization and tetramerization properties of the C-terminal region of chromogranin A: a thermodynamic analysis. Biochemistry 32:8816-8822

Zhang D, Lavaux T, Voegeli AC, Lavigne T, Castelain V, Meyer N, Sapin R, Aunis D, MetzBoutigue MH, Schneider F (2008) Prognostic value of chromogranin A at admission in critically ill patients: a cohort study in a medical intensive care unit. Clin Chem 54:1497-1503 